\title{
Characterization of cycle-to-cycle variations in a natural gas spark ignition engine
}

\author{
M. Reyes ${ }^{\mathrm{a}, *}$, F.V. Tinaut ${ }^{\mathrm{a}}$, B. Giménez ${ }^{\mathrm{a}}$, A. Pérez ${ }^{\mathrm{b}}$ \\ ${ }^{a}$ Department of Energy and Fluid Mechanics Engineering, University of Valladolid, Paseo del Cauce s/n, E-47011 Valladolid, Spain \\ ${ }^{\mathrm{b}}$ CIDAUT Foundation, Parque Tecnológico de Boecillo p. 209, E-47151 Boecillo-Valladolid, Spain
}

\section{H I G H L I G H T S}

- Study the influence of equivalence ratio and engine speed on cyclic variations.

- Diagnostic model with temperature dependant properties.

- Genetic algorithms applied to the analysis of the combustion inside an engine.

- Automatic adjustment of the diagnostic parameters.

- Application of the methodology to the study of the cyclic variability.

\section{A R T I C L E I N F O}

\section{Article history:}

Received 4 July 2014

Received in revised form 15 September 2014

Accepted 23 September 2014

Available online 23 October 2014

\section{Keywords:}

Cycle-to-cycle variations

Natural gas

Combustion diagnosis

Genetic algorithm

Spark ignition engine

\section{G R A P H I C A L A B S T R A C T}
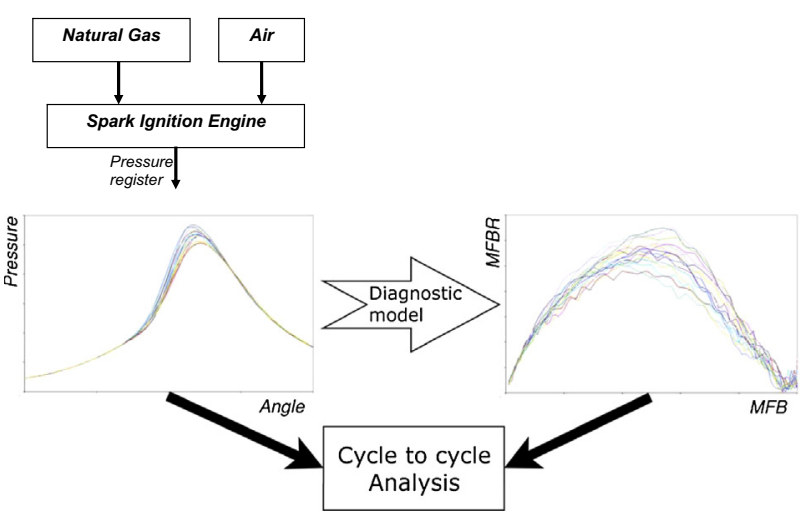

\section{A B S T R A C T}

In this work a study of the influence of the fuel/air equivalence ratio and engine rotational speed on the cycle-to-cycle variations in combustion in a natural gas spark ignition engine is presented. The study considers both classic estimators of cyclic dispersion and a new one, based on the burned mass and burning rate. The engine experimental conditions were as follows: Intake pressure $0.5 \mathrm{bar}$, while fuel/air equivalence ratio was changed from 1.0 to 0.63 , and engine rotational speed was varied from $1000 \mathrm{rpm}$ to $2500 \mathrm{rpm}$. For each equivalence ratio and engine speed, a diagnosis model is used to process the experimentally obtained combustion pressure data in order to provide combustion relevant results such as the mass burning rate at a cycle level. A procedure based on the use of genetic algorithms is used to obtain a very accurate and objective (without human intervention) adjustment of the optimum parameters needed for combustion diagnosis: angular positioning and pressure offset of the pressure register, dynamic compression ratio, and heat transfer coefficients. The model allows making the diagnosis of series of 830 consecutive engine cycles in an automatic way, increasing the objectivity of the combustion diagnosis. The paper focuses on using the values of the mass fraction burned computed from the pressure register and especially on the analysis of the combustion cycle to cycle variation in the natural gas fuelled engine. A new indicator for the study of cycle-to-cycle variations is proposed, i.e. the standard deviation of the mass fraction burning rate. The values of this new indicator are compared with other classic indicators, showing the same general trends. However, a deeper insight is provided on the combustion cyclic variation when the values of the new indicator are plotted as a function of the mass fraction burned, since this allows analyzing the cyclic variation along the combustion development in each cycle from a mass fraction burned of zero to one, with a relevant value at mass fraction burned of 0.5 . More important is that the consideration of the dependence of the combustion variables (density, flame front surface,

\footnotetext{
* Corresponding author.

E-mail address: miriam.reyes@uva.es (M. Reyes).
} 
combustion speed) on the mass fraction burned allows ensemble averaging of all registered cycles for each value of mass fraction burned. This permits using the ensemble averaged mass fraction burning rate as an estimator of combustion speed.

The analysis of the general trends of cyclic dispersion when engine speed and equivalence ratio are modified (1000, 1750 and $2500 \mathrm{rpm} ; 0.7,0.8,0.9$ and 1.0) indicate that cycle-to-cycle variations show, as expected, a strong dependence on the engine rotational speed, increasing the variation with engine $\mathrm{rpm}$. However, when the standard deviation of mass fraction burning rate is plotted as a function of mass fraction burned, there is a linear dependence on engine rpm, but only a very weak dependence on equivalence ratio. This means that the proposed estimator of cyclic dispersion is sensitive to only flow turbulent intensity and not to equivalence ratio.

(ㄷ) 2014 Elsevier Ltd. All rights reserved.

\begin{tabular}{|c|c|c|c|}
\hline \multicolumn{4}{|c|}{ Nomenclature } \\
\hline$A_{f}$ & spherical flame front area $\left(\mathrm{m}^{2}\right)$ & $u_{j}$ & internal energy $\left(\mathrm{J} / \mathrm{m}^{3}\right)$ \\
\hline$c_{m}$ & mean piston velocity $(\mathrm{m} / \mathrm{s})$ & $V$ & volume $\left(\mathrm{m}^{3}\right)$ \\
\hline CR & compression ratio $(-)$ & $V(\alpha)$ & cylinder volume for each crank angle $\left(\mathrm{m}^{3}\right)$ \\
\hline E & error & & \\
\hline $\mathrm{HCCI}$ & homogeneous charge compression ignition & Greek & \\
\hline ICE & internal combustion engine & & crank angle $\left({ }^{\circ}\right.$ or rad $)$ \\
\hline IMEP & indicated mean pressure $(\mathrm{Pa})$ & $\Phi$ & fuel/air equivalence ratio $\left(\varphi=\dot{m}_{\text {sto air }} / \dot{m}_{\text {air }}\right)$ \\
\hline$m$ & total mass $(\mathrm{kg})$ & $\mu$ & mean value \\
\hline MFB & mass fraction burned $(-)$ & $\rho$ & density $\left(\mathrm{kg} / \mathrm{m}^{3}\right)$ \\
\hline MFBR & mass fraction burning rate $\left(1 /{ }^{\circ}\right.$ or $\left.1 / \mathrm{s}\right)$ & $\sigma$ & standard deviation \\
\hline NG & natural gas & & \\
\hline$p$ & pressure $(\mathrm{Pa})$ & Subscript & \\
\hline$p_{m}$ & motored engine pressure $(\mathrm{Pa})$ & $b$ & burned \\
\hline$R_{j}$ & universal gas constant & $\max$ & maximum \\
\hline$S_{c}$ & combustion speed $(\mathrm{m} / \mathrm{s})$ & max & unburned fresh \\
\hline & temperature $(\mathrm{K})$ & wos & Woschni's \\
\hline TDC & top dead center & & \\
\hline
\end{tabular}

\section{Introduction}

Because of concerns for the environment protection and energy shortages, much effort has been concentrated on the utilization of alternative fuels in internal combustion engines (ICE). Alternative fuels are clean when they are compared to conventional ones derived from petroleum in ICE. Natural gas (NG) is considered to be a possible alternative fuel due to its higher octane number and properties. NG is a mixture of different gases where methane is its main component (75-98\% of methane, $0.5-13 \%$ of ethane and $0-2.6 \%$ of propane [1]). NG combustion produces lower emission than that of conventional fuels because the chemical structure of NG is less complex, together with the non-existence of fuel evaporation [2]. The high octane number of NG (between 120 and 130) allows the engine to operate at high compression ratios, because it gives a high anti-knocking potential [3].

In general, combustion in spark-ignition engines varies considerably from cycle to cycle [4]. Many studies have been carried out in order to find the main causes of this effect $[5,6]$. These variations are associated with considerable variations in flame speed and combustion duration [7]. The effect of cyclic dispersion is also described by Litak et al. [8,9]. These variations produce a reduction in the mean effective torque as much as $20 \%$ [10].

Cyclic dispersion has been classically evaluated by statistical processing of the maximum pressure $\left(p_{\max }\right)$ and the angle in which this maximum pressure is reached $\left(\alpha_{P \max }\right)$ [11]. It has also been studied with the variation in the heat released during the combustion $[12,13]$. Recently it also has been studied in homogeneous charge compression ignition ( $\mathrm{HCCl}$ ) engine processes [14], compression ignition engines [15] and also by using CFD simulations [16]. A traditional [17-22] estimator of the cycle-to-cycle variation is the Coefficient of Variation in Indicated Mean Pressure, $\operatorname{COV}_{\text {IMEP. In this }}$ paper, the authors propose complementary considering the variation of the mass fraction burning rate of each individual cycle to characterize cyclic variation, as explained later (Fig. 1).

Cycle-to-cycle dispersion studies carried out using combustion diagnosis require a lot of effort because each cycle requires adjusting some parameters such as pressure offset, angular positioning and others, before an accurate analysis can be performed. This implies that cyclic dispersion studies conducted by manual or traditional diagnostic techniques include some degree of subjectivity in the results. Moreover, in many studies, the combustion models were simple as the one described by Li and Yao [23].

A complex diagnostic model, with temperature dependent thermodynamic properties and heat loses, is used to evaluate the pressure data obtained experimentally. The model has been

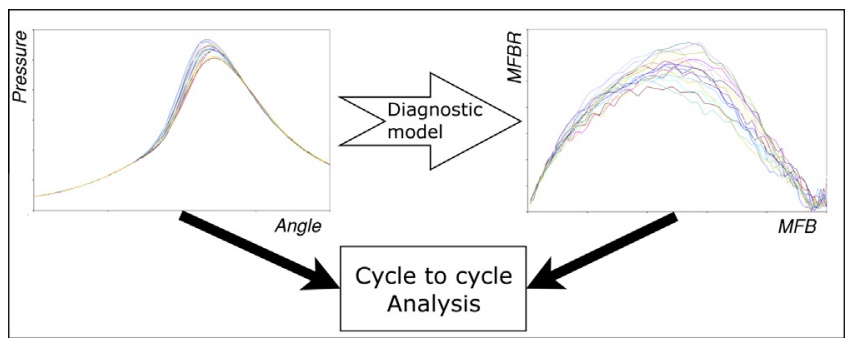

Fig. 1. Classical and proposed ways of analyzing cycle to cycle variation outline. 
improved by the use of genetic algorithms in order to determine some parameters needed for an accurate diagnosis. For each cycle, the parameters of the diagnosis (as pressure offset and angular position of the pressure data) are adjusted by the genetic algorithm techniques. This complete model is run over six series of 830 consecutive engine pressure data. More details about the model can be found in the work of Reyes et al. [24].

Genetic algorithms were firstly introduced by Holland [25]. Genetic algorithms belong to a group of heuristic mathematical techniques generally used to solve optimization problems that are known as evolutionary algorithms. Since its introduction, genetic algorithms have been widely used to solve diverse optimization problems in different fields of thermodynamic and fluid science $[26,27]$.

Turbulence speeds up the combustion process; this raises the velocity of combustion an order of magnitude above the laminar combustion velocity [28]. Some authors [29,30] have investigated the turbulence in the combustion chamber using different parameters and techniques to characterize the turbulent intensity using fluid velocity measurements in a point of the combustion chamber. A study of the velocity field is carried out by using the ensembleaveraging approach [31].

The flame front position can be calculated as a function of the geometry and the volume of the burned mass. For a fixed equivalence ratio, the MFB (Mass Fraction Burned) and the volume of burned mass are related. In consequence for a fixed equivalence ratio a given value of MFB indicates the position of the flame front and is not dependent of the crankshaft angle if the minor piston displacements are neglected.

In the present study, the concept of ensemble averaged values is applied to the combustion velocity for different values of MFB in order to analyze the phenomenon of cycle-to-cycle variation, see Fig. 1.

The main objective of this work is to evaluate the relative influence of the equivalence fuel/air ratio and the engine rotational speed on the cycle-to-cycle variations produced in a single cylinder spark ignition engine fuelled with natural gas, through a thermodynamic combustion diagnostic model that includes genetic algorithms for parameter adjusting. A new estimator of cyclic dispersion is proposed: The standard deviation of the mass fraction burning rate. Plotting this estimator as a function of the mass fraction burned allows a better identification of the evolution of the cyclic deviation along combustion development, from spark, main part and last part of combustion.

\section{Methodology}

\subsection{Experimental apparatus and procedure}

The tests were performed in a single-cylinder, four-stroke, air cooled MINSEL M380 engine coupled to an asynchronous machine with a constant engine rotation speed. This engine was originally designed to be a compression ignition engine, with flat cylinder head and a bowl-in piston combustion chamber. A number of changes were made to transform it into a spark ignition engine. The original injector was substituted by a spark plug and a modification in the piston was carried out in order to transform the combustion chamber and to reduce the original compression ratio. The specifications of the cylinder are: $80 \mathrm{~mm}$ bore, $75 \mathrm{~mm}$ stroke, and 11.4 compression ratio.

This engine was coupled to a $5.5 \mathrm{~kW}$ LEROY SOMER asynchronous machine that was used for motoring and braking, see Fig. 2. The engine was instrumented for the measurement of mean engine performance values to determine when it is stabilized, such us, intake and exhaust pressures, and intake, exhaust, cylinder head and oil temperatures. When the engine is stabilized in a certain operating point, the instantaneous pressure in the combustion chamber is registered and stored in a Yokogawa DL750 Scopecorder. IMEP at each operating point is then calculated from the instantaneous pressure plot.

The experiments have been carried out in two different stages. In the first stage, engine rotational speed was maintained at $1500 \mathrm{rpm}$ and intake pressure was set at $0.5 \mathrm{bar}$, the angle of spark ignition was set to obtain the maximum brake torque for each test, and the fuel/air equivalence ratio $(\Phi)$ was varied from 0.63 to 1.0 . In the second stage of the experimentation, intake pressure was also set around 0.5 bar and fuel/air equivalence ratio was varied from 0.7 to 1.0 , while engine rotational speed was modified from $1000 \mathrm{rpm}$ to $2500 \mathrm{rpm}$, to discern the effect of the engine rotational speed on the cyclic dispersion.

\subsubsection{Cylinder pressure measurement}

In the experimental setup, the pressure inside the cylinder was measured by using a piezo-electric sensor AVL GU21D (maximum calibration error of $0.06 \%$ ). This sensor was connected to a KISTLER 5018A1000 charge amplifier (maximum calibration error of 0.3\%). The output signal of the charge amplifier was recorded on a Yokogawa DL750 Scopecorder ( 16 bits AD converter). The estimated error of the pressure acquisition is $0.36 \%$ over the measuring range).

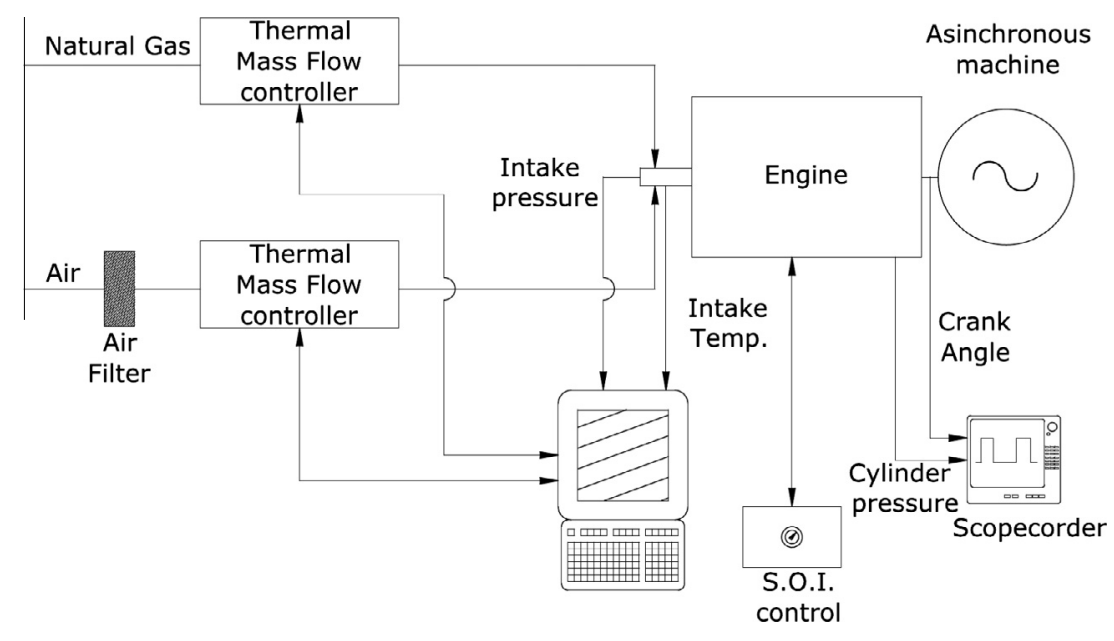

Fig. 2. Schematic diagram of the engine setup. 
The crankshaft angle was measured using a free end AVL 360C.03 angular encoder. This encoder has 600 marks per revolution: i.e. a 0.6 degrees resolution and also a single pulse per revolution signal. In order to synchronize the pressure signal with the crankshaft angle, the option of an external clock was activated in the Scopecorder.

\subsubsection{Mass flow set and measurement}

The fuel used during the experiments was natural gas (NG). The inlet mixture of NG and air was made by using two BROOKS thermal mass flow controllers. These controllers are equipped with a proportional valve and an actuator. Therefore, the mass flow rate could be measured and controlled at once. A $5853 \mathrm{~S}$ model was used for the air and a 5851S model was used for the NG. The mixture of the NG and air was formed in the inlet manifold, so the level of premixing was high and almost constant.

\subsection{Models employed}

\subsubsection{Thermodynamic model}

A one zone, zero dimensional thermodynamic model has been used to perform the diagnosis of premixed combustion from the experimentally measured in-cylinder pressure. The model solves the energy conservation equation during the closed valves interval by using the ideal gas state equation to relate pressure, volume and temperature (Eqs. (1) and (2)).

$U_{j}-U_{j-1}=\dot{Q}_{W_{m}} \cdot \Delta t-1 / 2\left(p_{j}+p_{j-1}\right)\left(V_{j}-V_{j-1}\right)$

$p_{j} V_{j}=m R_{j} T_{j}$

The subscript $j$ refers to a time point, while $j-1$ refers to the previous one. $U$ is total internal energy, $\dot{Q}_{W_{m}}$ is the average heat transferred through the walls, calculated using Woschni's heat transfer coefficient, $p$ is the pressure, $V$ is volume, $R$ is the ideal gas constant and $T$ is the absolute temperature. The total trapped mass $(m)$ is constant during all the cycle because the leakage flow is neglected. IMEP, $p_{\max }$ and $\alpha_{\max }$ are easily found from experimental data, while the fraction of mass burned (MFB-mass fraction burned) obtained as the ratio between the mass burned until a particular crankangle and the total trapped mass is the most relevant model result.

Previous equations are solved by using the following procedure: For the initial angle, total mass is unburned and is determined by the mass flow meters data and incremented with a mass of residuals predicted using a gas exchange process model for the test conditions. The composition of the unburned and burned mass is known because the equivalence ratio and residuals are known and complete combustion is assumed. The temperature is calculated with the ideal gas state equation.

The specific internal energy in the burned $u_{b}$ and unburned $u_{u}$ zones are calculated with a thermal estate equation, as a function of the composition and temperature, with the correlations published in the NIST tables [32] where sensible and formation energy are included. The total internal energy of the cylinder contents is weighted with the mass fraction burned (Eq. (3)).

$$
U(T)=m\left(\operatorname{MFB} \cdot u_{b}(T)+(1-\mathrm{MFB}) \cdot u_{u}(T)\right)
$$

In order to calculate the next angle situation, an increment of burned mass is assumed. An error in terms of energy is computed with Eq. (1). This is iteratively solved to adjust the increment of burned mass to satisfy the energy equation.

Heat transferred through the walls is computed by means of Woschni's expression as shown in Eq. (4).

$$
\begin{aligned}
h= & 0.013 \cdot d_{p}^{-0.2} \cdot p^{0.8} \\
& \cdot T^{-0.53}\left(k_{\text {wos } 1} 2.28 c_{m}+k_{\text {wos } 2} \cdot 0.00324 \frac{V_{d} T_{i c}}{p_{i c}}\left(p-p_{m}\right)\right)^{0.8}
\end{aligned}
$$

where $h$ is the coefficient of heat transfer, $d_{p}$ is the diameter of the piston, $c_{m}$ is the mean piston speed. $T_{i c}$ and $p_{i c}$ are the temperature and pressure when the intake valve closes and $p_{m}$ is the motored engine pressure. The parameters $k_{\mathrm{wos} 1}$ and $k_{\mathrm{wos} 2}$ are multipliers that have to be adjusted. More details of the thermodynamic model can be found in Reyes et al. [24].

\subsubsection{Genetic algorithm}

With the purpose of correctly process the pressure data with the above mentioned thermodynamic model, parameters as experimental pressure offset, crank angle positioning, compression ratio and others should be adjusted. In this work the authors use an application of genetic algorithms to solve the positioning of the pressure diagram and to adjust the rest of parameters of the engine that in any cases are difficult to know precisely.

Genetic algorithms are based on Darwin's Theory of Evolution: the best adapted individuals are selected to survive and to be the progenitors of the subsequently generation. Thus by this selection, the best genetic combination is transmitted to the next generation of individuals. This procedure, repeated numerous generations, ends with a new, better-adapted individual. This method is programmed to obtain the most precise combustion diagnosis for each engine cycle. This ensures that the best determination of MFB is obtained for each cycle. Any genetic algorithm used to solve an optimization problem has several concepts in common: individual, codification, fitness function, selection and genetic operators.

The total individuals of the population are, $N_{\text {par }}^{2}$ and they are obtained with all the combinations of pairs of $N_{\text {par }}$ individuals. The crossover function is applied to the total individuals to obtain the initial population. The criterion to select the best adapted individuals is done using the fitness function $Z$ (applied to the MFB calculated with the diagnostic model for each individual codification).

Each individual is characterized by its codification. The parameters that must be adjusted by the algorithm are: Angular position, pressure offset, compression ratio and a multiplier of the heat transfer coefficient ( $k_{\text {wos } 1}$ and $\left.k_{\text {wos } 2}\right)$, calculated using Woschni's correlation [33]. The evaluation criterion to select the better adapted individuals is a fitness function which is applied to the result of diagnostic model, run with the parameters of each individual. The general objective of the optimization procedure is to reduce the error of the fitness function, both for motored (mass fraction burned zero) and combustion (mass fraction burned unity) conditions. Detailed information of the crossover function and the $Z$ function can be found in Reyes et al. [24] where a full description of the genetic algorithm is presented with supplementary information.

\section{Results and discussion}

\subsection{Data analysis and diagnostic methodology}

To perform a research about the cycle-to-cycle variations, an elevated number of engine cycles must be studied for each experimental set of conditions (i.e. regime, load, etc). Some authors choose between 120 and 2000 cycles $[4,8,11,34]$ to obtain a representative sample. With the purpose of obtaining a correct diagnosis, parameters related to the experimental measurement process, i.e. angular positioning, heat transfer multipliers, compression ratio and pressure offset, must be determined, if possible not including any bias. 
Table 1

Values of $k_{\text {wos } 1}$ and $k_{\text {wos } 1}$ obtained after the second execution of the diagnostic tool for each fuel/air equivalence ratio tested.

\begin{tabular}{lll}
\hline$\Phi$ & $k_{\text {wos } 1}$ & $k_{\text {wos } 2}$ \\
\hline 1.0 & 1.08 & 1.29 \\
0.9 & 0.76 & 0.89 \\
0.79 & 0.67 & 1.06 \\
0.74 & 0.63 & 0.68 \\
0.67 & 0.54 & 0.72 \\
0.63 & 0.96 & 1.03 \\
\hline
\end{tabular}

The set of experiments for this work consisted of first the acquisition in the engine of the pressure data of 20 consecutive cycles under motored conditions and then the acquisition of the pressure data of six series of 830 consecutive cycles under combustion conditions, each series with a different equivalence ratio $(\Phi)$. The equivalence ratios tested were: $1.0,0.9,0.79,0.74,0.67$ and
0.63. Inlet pressure was kept constant ( 0.5 bar), while engine speed was initially fixed at $1500 \mathrm{rpm}$ and pressure data were recorded when the engine reached steady conditions.

The diagnostic model is first applied to the pressure trace of the 20 cycles under motored engine conditions in the $[-100,140]$ crank angle interval (being $0^{\circ}$ the combustion TDC position). The genetic algorithm is run on the diagnostic model results in order to obtain the adjusting values that reduce the error of the fitness function. Initially a constant value of 1 for the parameters $k_{\text {wos } 1}$ and $k_{\text {wos2 }}$ is used. The preliminary results of this fist adjusting step are: A correction of the angular position of -0.5 (with a standard deviation of 0.21 crank angle degrees) and a compression ratio of 10.8 (with a standard deviation of 0.126 ). The pressure offset is left free, with a value calculated independently for each cycle.

In a second step, the diagnostic tool is run over all the combustion cycles of each operating condition (six different values of $\Phi$ ). In this case, the values of angular position of the TDC and compression ratio are the values previously obtained in the motored engine
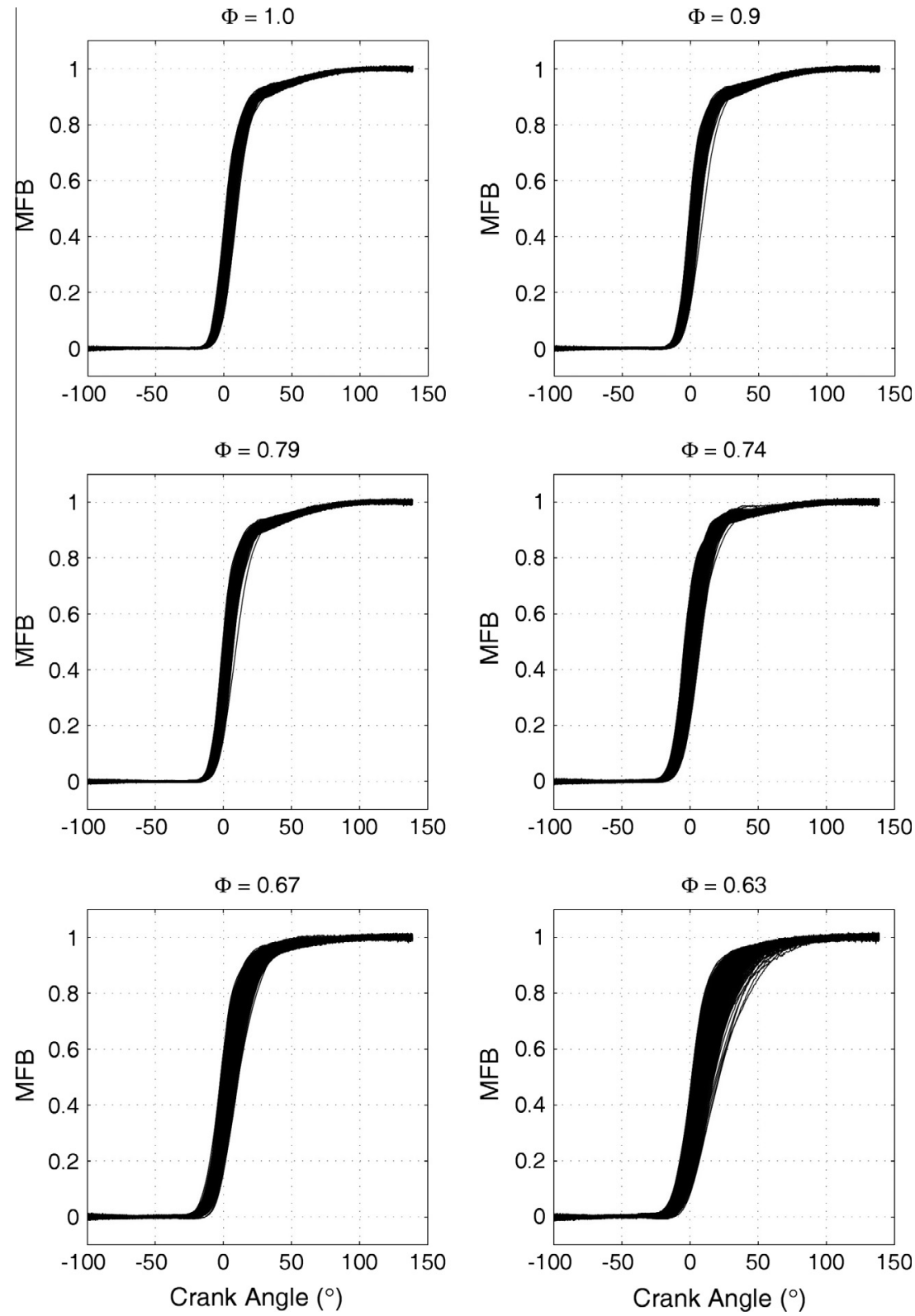

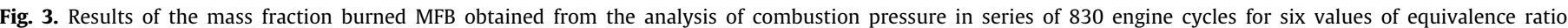
(1500 rpm) 
test. The best values of pressure offset and the parameters $k_{\mathrm{wos} 1}$ and $k_{\text {wos2 }}$ for each test point are then obtained by the genetic algorithm (Table 1.). Pressure offset is again left free.

In a third and last step, all the genetic algorithm parameters are fixed to the previously obtained values, except for the pressure offset, which is always left free.

\subsection{Cycle to cycle dispersion studies}

\subsubsection{Influence of the fuel/air equivalence ratio}

Cyclic dispersion analysis has been carried out over six series of 830 consecutive cycles, varying the equivalence ratio. The results of MFB obtained from all pressure data are presented in Fig. 3, where 830 cycles are considered for each equivalence ratio (all cases at $1500 \mathrm{rpm}$ ). The low slope at the end of combustion, from $\mathrm{FMQ} \approx 0.95$ to the end of combustion, is due to the shape of the combustion chamber. When the flame front enters the small gap between the piston and the cylinder head cools down and this reduces its combustion velocity; probably a part of this mixture is burned more slowly in a secondary combustion process.

An initial estimation of the importance of cycle-to-cycle variation is made with the coefficient of variation (COV) of the indicated mean pressure $[18,19]$, calculated as the ratio of the standard deviation and the mean value (Eq. (5)).

$$
\begin{aligned}
& \operatorname{COV}_{\text {IMEP }}=\frac{\sigma_{\text {IMEP }}}{\mu_{\text {IMEP }}} \cdot 100 \% \\
& \mu_{\text {IMEP }}=\frac{1}{N_{c}} \sum_{i=1}^{N_{c}} x_{i} \\
& \sigma_{\text {IMEP }}=\left[\frac{1}{N_{c}} \sum_{i=1}^{N_{c}}\left(x_{i}-\mu_{\text {IMEP }}\right)^{2}\right]^{1 / 2}
\end{aligned}
$$

for a given series of combustion cycle being $\left\{x_{i}\right\}, i=1,2,3, \ldots, N_{c}$ the IMEP of a particular cycle.

For a given series of engine cycle, the $\mathrm{COV}_{\text {IMEP }}$ provides a single overall numerical value characterizing the variability in the cycleto-cycle data. Then the $\operatorname{COV}_{\text {IMEP }}$ is a helpful value to compare the degree of variation between series even when their mean values are fairly different from each other.

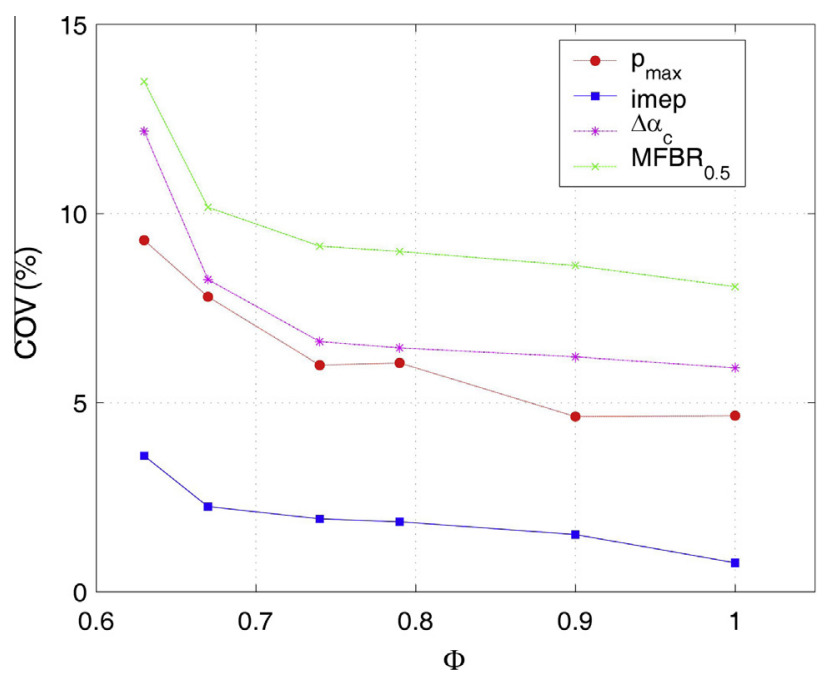

Fig. 4. Values of coefficient of variation (COV) of the four combustion variables for the six different equivalence ratios considered (1500 rpm).
The results of the COV of indicated mean pressure (IMEP), and of other three estimators of cyclic variation (explained below) are shown in Fig. 4.

It is accepted [6], that, in order to ensure regular running of the engine, the coefficient of variation of the IMEP must be smaller than $5 \%$. Notice that this limit is not reached in any of the tests, including the leanest operating condition ( $\Phi=0.63$ ) that is near the lean limit.

As the full diagnosis is performed for each cycle, other values relative to combustion development can be computed, in order to check the influence of the equivalence ratio on the cyclic dispersion. Thus the second estimator for cyclic variation is the COV of the maximum combustion pressure $\left(p_{\max }\right)$. The mean value and standard deviation of the values of $p_{\max }$ corresponding to all cycles are obtained and the coefficient of variation $\operatorname{COV}_{\text {pmax }}$ is computed similarly as for the IMEP and is also represented in Fig. 4. The third estimator is the variation in combustion duration $\left(\Delta \alpha_{c}\right)$. This is defined as the angular interval from $10 \%$ to $90 \%$ of MFB. Similarly as for the other variables, the $\operatorname{COV}_{\Delta \alpha c}$ has been computed and is plotted in Fig. 4.

Finally a fourth estimator of the cyclic variability is calculated from the diagnosis results: The value of the coefficient of variation $\mathrm{COV}_{\mathrm{MFBR}}$ of the mass fraction burning rate (MFBR) for a given value of the mass fraction burned. For this latter, the authors have chosen a representative value of $50 \%$ of mass fraction burned. Then the $\operatorname{COV}\left(\mathrm{MFBR}_{0.5}\right)$ is represented also in Fig. 4.

Notice that IMEP, $p_{\max }$ and $\Delta \alpha_{c}$ are magnitudes that take into account how the combustion pressure has evolved from the beginning of combustion and include averaged information of the history of the cycle. They can be considered as cycle integrated values (this is strictly true for IMEP, and qualitatively right for $p_{\max }$ and $\Delta \alpha_{c}$ ). In contrast, MFBR for a given MFB is a single value representative of combustion rate. This makes the COV of MFBR higher than the ones obtained for the cycle integrated values.

As can be seen in Fig. 4, the COV of all the estimators present the same tendency with the equivalence ratio, showing that leaner mixtures have higher levels in cyclic dispersion. The comparison among the four estimators show different absolute values, but with similar trends, increasing their values as the mixture is leaner, with a relatively strong increase for the leanest mixtures $(\Phi=0.67$ and 0.63 ). All the COV's can be ordered for each equivalence ratio resulting in:

$\operatorname{COV}_{\text {MFBR } 0.5}>\operatorname{COV}_{\Delta \alpha_{c}}>\operatorname{COV}_{p_{\max }}>\operatorname{COV}_{\text {IMEP }}$

If the standard deviations $\sigma$ of the previously mentioned quantities are represented versus the equivalence ratio (Fig. 5), the same tendency of COV values is observed except for the $\sigma_{\mathrm{MFBR} 0.5}$,

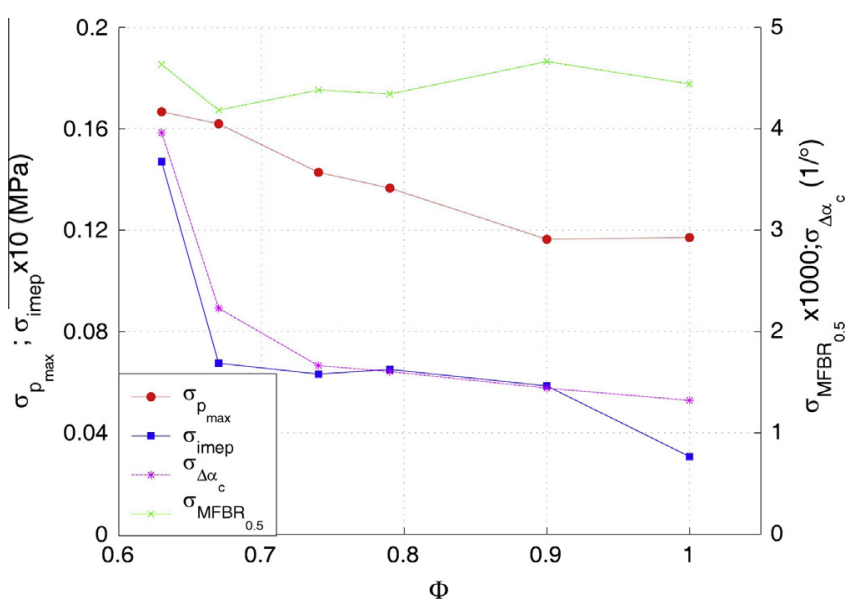

Fig. 5. Values of standard deviation $\sigma$ of the four indicators for the six different equivalence ratios $(1500 \mathrm{rpm})$ 
that has not a clear tendency with the equivalence ratio. This relative independence of equivalence ratio is further discussed in the next section.

\subsubsection{Relationship between ensemble averaged mass fraction burning} rate and combustion velocity

It is interesting to express the relationship between MFBR and the turbulent combustion velocity, $S_{c}$, see Eq. (12),

$\frac{d(\operatorname{MFB}(\alpha))}{d \alpha}=\frac{d\left(\frac{m_{b}(\alpha)}{m}\right)}{d \alpha}=\frac{1}{m} \frac{d\left(m_{b}(\alpha)\right)}{d t} \frac{d t}{d \alpha}$

$\frac{d(\operatorname{MFB}(\alpha))}{d \alpha}=\operatorname{MFBR}(\alpha)=\frac{\dot{m}_{b}(\alpha)}{m} \frac{1}{\omega}$

$\dot{m}_{b}(\alpha)=\rho_{u}(\alpha) A_{f}(\alpha) S_{c}(\alpha)$

$\operatorname{MFBR}(\alpha)=\frac{\rho_{u}(\alpha) A_{f}(\alpha)}{m \omega} S_{c}(\alpha)$

where $\rho_{u}$ is the unburned density, $A_{f}$ is the flame front surface, $S_{c}$ is the turbulent combustion velocity (the three variables for a given value of crank angle $\alpha$ ), $m$ is the total mass and $\omega=d \alpha / d t$ is the engine angular velocity (constant in each test). For a specific crank angle $\alpha, \rho_{u}$ and $A_{f}$ may have slightly different values from cycle to cycle.

Considering all cycles of a given operating point, when the amount of burned mass is the same (i.e. the same value of MFB), if we assume that the piston position varies only slightly during combustion, $\rho_{u}$ and $A_{f}$ can be considered similar for all the cycles (because pressure and temperatures must be similar, since the mass burned and the volume are similar). Under this assumption, the ensemble average value of MFBR (( $\overline{\text { MFBR }})$ for each cycle $i$ turns out to be proportional to the average value of $S_{c}$, as can be expressed in Eq. (13), where the summations are extended to the values of each cycle (defined by $i$ ) up to $N_{c}$, the number of cycles of a pressure record, and the dependence on $\alpha$ in Eq. (12) can be rewritten as a dependence on MFB:

$\overline{\operatorname{MFBR}}(\mathrm{MFB})=\frac{1}{N_{c}} \sum_{i=1}^{N_{c}} \operatorname{MFBR}(\operatorname{MFB}, i)=\frac{1}{N_{c}} \sum_{i=1}^{N_{c}} \frac{\rho_{u}(\mathrm{MFB}) A_{f}(\mathrm{MFB})}{m \omega} S_{c}(\mathrm{MFB}, i)$

$$
=\frac{\rho_{u}(\mathrm{MFB}) A_{f}(\mathrm{MFB})}{m \omega} \overline{S_{c}}(\mathrm{MFB})
$$

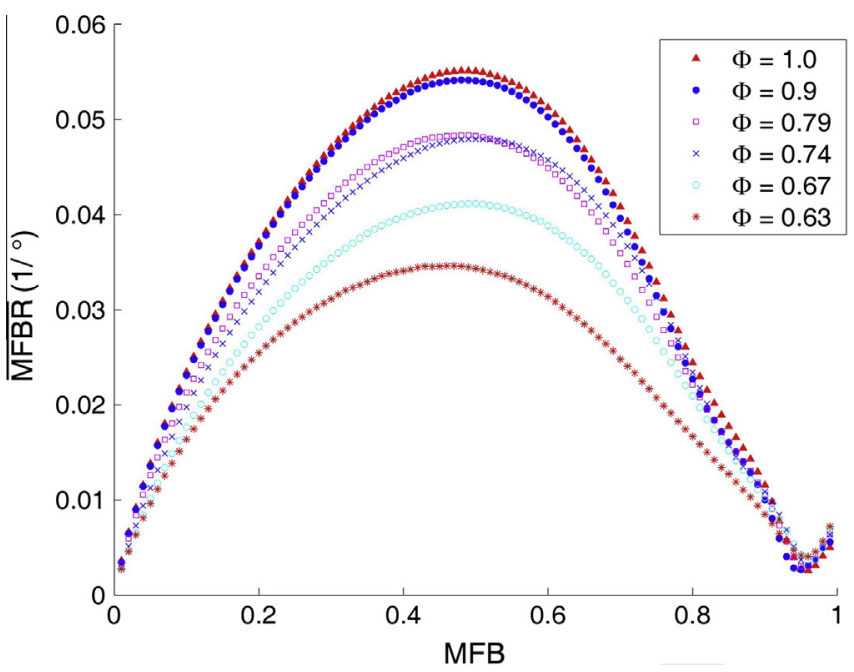

Fig. 6. Ensemble averaged values of mass fraction burning rates $\overline{M F B R}$ as a function of mass fraction burned for each equivalence ratio (1500 rpm).

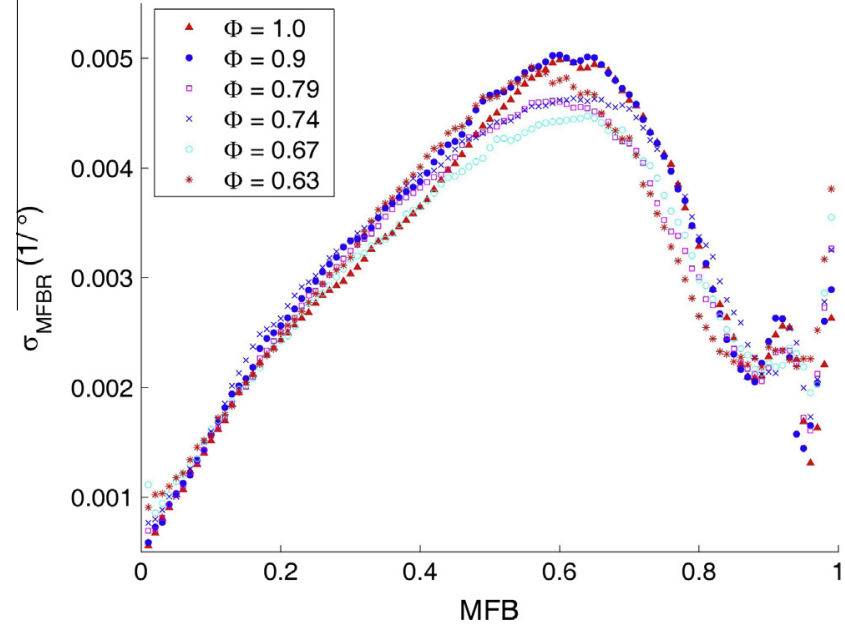

Fig. 7. Standard deviation of mass fraction burning rate $\sigma_{\mathrm{MFBR}}$ as a function of mass fraction burned MFB for each equivalence ratio (1500 rpm).

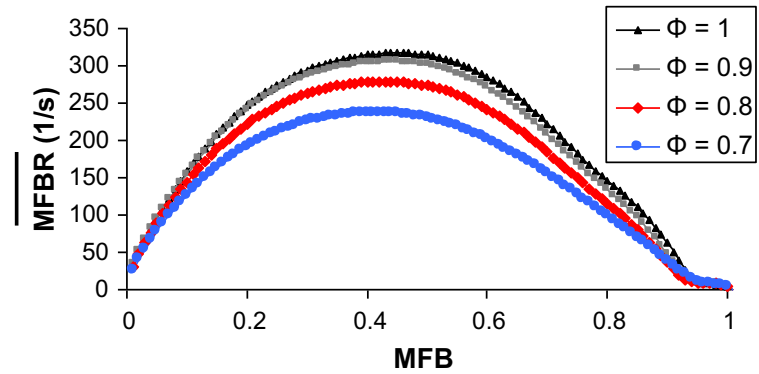

(i) $1000 \mathrm{rpm}$

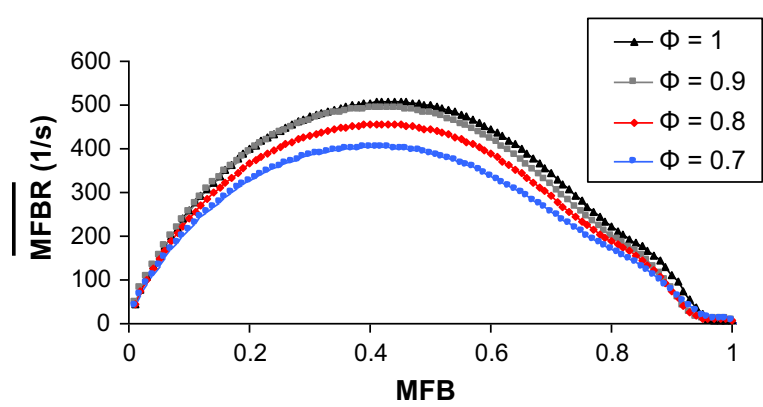

(ii) $1750 \mathrm{rpm}$

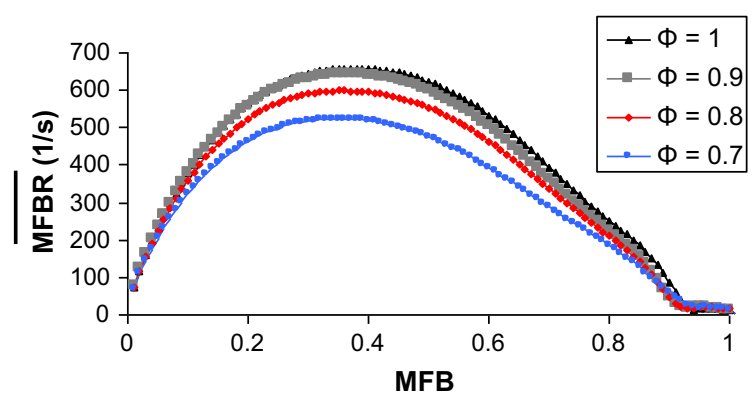

(iii) $2500 \mathrm{rpm}$

Fig. 8. Ensemble averaged mass fraction burning rates $\overline{\mathrm{MFBR}}$ as a function of mass fraction burned for each equivalence ratio at different engine speeds.

The turbulent fluctuation of the combustion speed $\sigma\left(S_{c}\right)$ can then be estimated from the standard deviation of the burning rate $\sigma$ (MFBR), since from Eq. (13) it can be seen that they are proportional for each value of MFB, Eq. (14). 


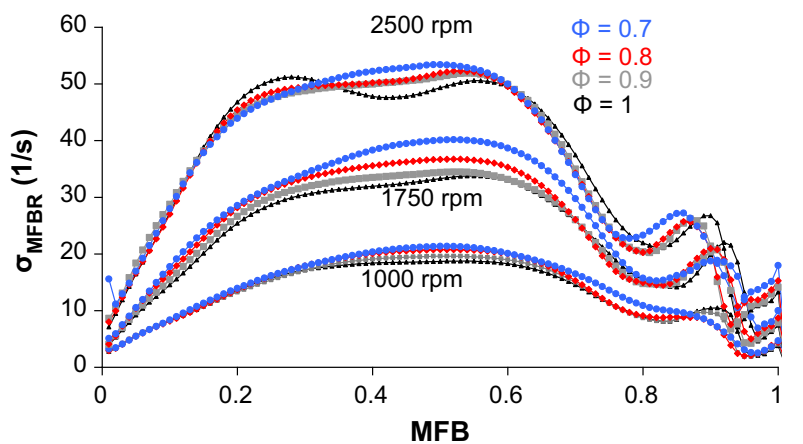

Fig. 9. Standard deviation of mass fraction burning rate $\sigma_{\mathrm{MFBR}}$ as a function of mass fraction burned MFB for each equivalence ratio at different engine speeds.

$\sigma(\mathrm{MFBR})=\frac{\rho_{u} A_{f}}{m \omega} \sigma\left(S_{c}\right)$

For all cycles and equivalence ratios studied, the ensemble average of MFBR, ( $\overline{\mathrm{MFBR}})$ for each MFB was computed, calculating the mean value and the standard deviation for each test (Eq. (15)).

$\sigma(\mathrm{MFBR})=\sqrt{\frac{1}{N_{c}} \sum_{i=1}^{N_{c}}[\operatorname{MFBR}(\operatorname{MFB}, i)-\overline{\operatorname{MFBR}}(\mathrm{MFB})]^{2}}$

The results are shown in Fig. 6 where the ensemble average of the MFBR as a function of MFB is represented with the equivalence ratio as independent parameter. Each line represents the ensemble average in phase for each value of MFB of the 830 cycles of a test. Fig. 6 shows that the influence of the equivalence ratio on burning rate is clear, since higher equivalence ratios cause have higher values of MFBR, as can be expected due to the influence of the laminar combustion velocity on the turbulent combustion velocity and then on MFBR through Eq. (13).

Another interesting result is shown in Fig. 7 where the standard deviation of the MFBR ( $\sigma_{\text {MFBR }}$, Eq. (15)) is represented for each MFB.

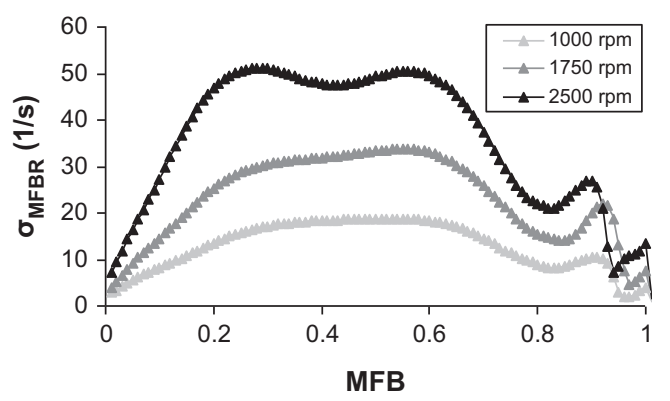

(i) $\Phi=1$

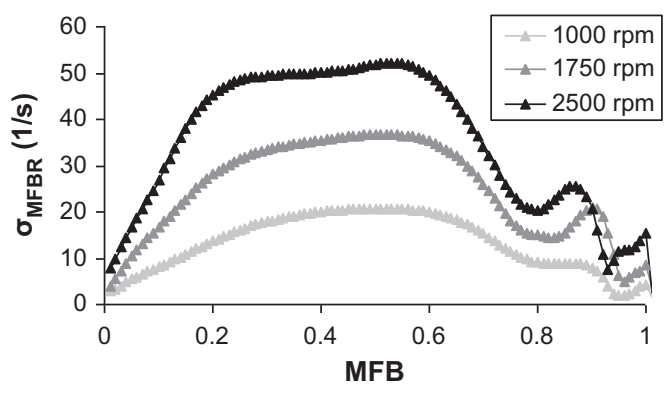

(iii) $\Phi=0.8$
It can be observed that in this case there is almost no influence of equivalence ratio for the tested mixtures. This result is in agreement with the trend of $\sigma\left(\mathrm{MFBR}_{0.5}\right)$ presented in Fig. 5. This is important and can be stated as: When the burning rate is plotted as a function of the mass fraction burned, only the influence of turbulence remains, while the influence of equivalence ratio (through laminar combustion speed) is almost negligible. On the contrary, the other estimators of cyclic dispersion (IMEP, $p_{\max }$ and $\Delta \alpha_{c}$ ), that we have named "integrated," retain the dependence on equivalence ratio (as shown in Fig. 5). For that reason, the type of representation of relevant variables as functions of mass fraction burned is useful to better identify the origin of the cyclic variation.

\subsubsection{Combined effects of the engine rotational speed and equivalence ratio}

The tests in previous sections were carried out at a fixed engine rotational speed of $1500 \mathrm{rpm}$. This section focuses on the effects of engine speed on the combustion behavior and cyclic variations at certain equivalence ratios. Prior to these experiments the engine piston was changed and is slightly different from that used in the previous section, that means, the compression ratio is higher, 11.4. Fig. 8 presents results of the ensemble average of the MFBR as a function the MFB values for different engine speeds (1000 rpm, $1750 \mathrm{rpm}$ and $2500 \mathrm{rpm}$ ) with four equivalence ratios. According to Eq. (12), $\overline{\text { MFBR }}$ is an estimator of the combustion speed. The unit of $\overline{M F B R}$ is changed to a time basis (1/s) to eliminate the bias of the engine speed on the results (notice the change of scale of vertical axes). As can be seen, for each engine speed, the, $\overline{M F B R}$ increases with the equivalence ratio due to its effect on laminar combustion speed. The effect of engine speed increases, $\overline{M F B R}$ although less than linearly. For example, a change of engine speed from 1000 to $2500 \mathrm{rpm}$ (a factor of 2.5) results in a change on, $\overline{\text { MFBR }}$ of about 2.2.

To identify the combined effect of engine speed and equivalence ratio on cyclic dispersion, Fig. 9 shows the standard deviation of the MFBR as a function of MFB for three different rotational engine speeds when the fuel/air equivalence ratio is varied from 0.7 to 1.0.

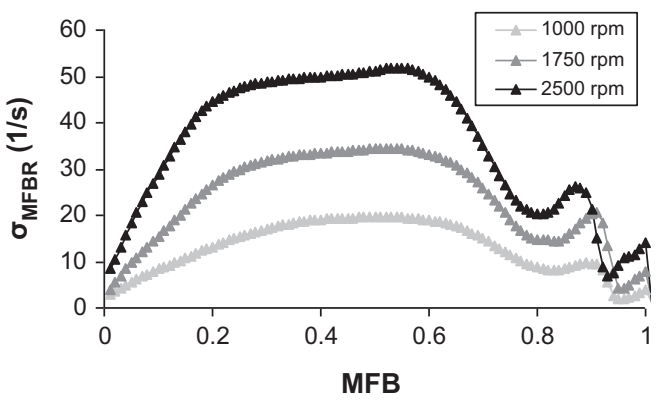

(ii) $\Phi=0.9$

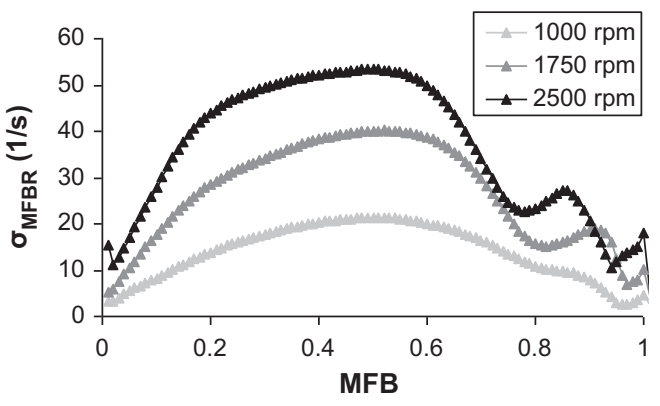

(iv) $\Phi=0.7$

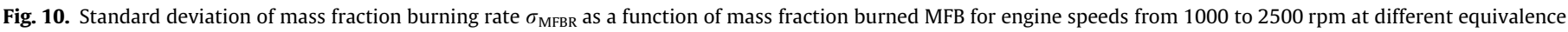
ratio. 


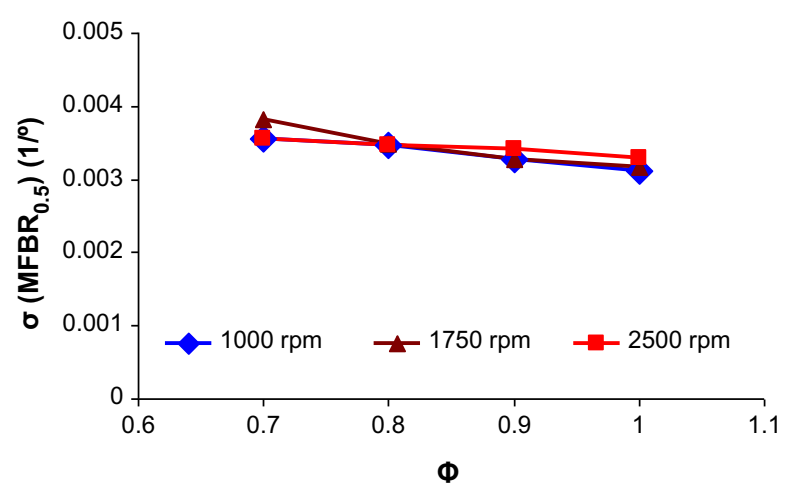

(i) $\sigma(\operatorname{MFBR} 0.5)\left(1 /^{\circ}\right)$

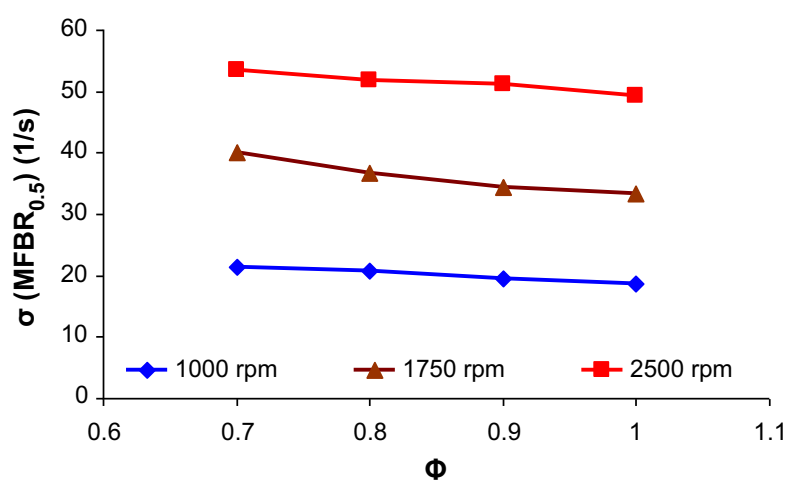

(ii) $\sigma(\operatorname{MFBR} 0.5)(1 / \mathrm{s})$

Fig. 11. Standard deviation of the MFBR in different units $\left(1 / \mathrm{s}\right.$ and $\left.{ }^{\circ}\right)$ when $50 \%$ of mass is burned versus the equivalence ratio for different engine speed.

In this figure it can be seen that cyclic dispersion again shows little dependence on the fuel/air equivalence ratio of each mixture, while the dependence on engine speed is much bigger (notice the change of scale in the vertical axes).

Fig. 10 presents the same results of the standard deviation of the MFBR as a function of MFB of Fig. 9, but plotted separately for each value of the four different equivalence ratios $(0.7,0.8,0.9$ and 1$)$, showing the dependency on engine speed (1000-2500 rpm) more clearly. In this figure it can be seen that when the engine operates at low speed the standard deviation of MFBR is small (and also the value of, $\overline{\text { MFBR }}$ shown in Fig. 8), but as the engine speed increases, the standard deviation also increases.

Fig. 11 provides an additional interpretation of the effect of engine speed and equivalence ratio. The values of $\sigma\left(\mathrm{MFBR}_{0.5}\right)$ are plotted for each operating condition, with the equivalence ratio on the $x$-axis. In the lower part, the values of $\sigma\left(\mathrm{MFBR}_{0.5}\right)$ are in units of $(1 / \mathrm{s})$, and in that case, the effect of engine rpm is almost linear on this estimator of cyclic dispersion. In the upper part, the values of $\sigma\left(\mathrm{MFBR}_{0.5}\right)$ are in units of $\left(1 /^{\circ}\right)$, as they are obtained by dividing the previous ones by the engine rpm. As can be seen in the upper part, the lines for the three engine rpm merge together, showing again that the cyclic dispersion is linear with engine speed. On the other hand, both parts of the figure show that the dependence on equivalence ratio is much smaller, in spite of the small increase of the standard deviation as the mixtures are leaner.

\section{Conclusions}

In this work the cycle-to-cycle variations in a natural gas spark ignition engine with different fuel/air equivalence ratios and engine rotational speeds have been studied, to provide a deeper insight of the influence of those operating conditions.
A method for characterizing the cycle-to-cycle variation has been used by considering classic estimators and a new estimator, based on the mass burning rate and its deviation. The method requires first the use of a diagnostic tool based on a complex combustion model that is applied on combustion pressure records for an elevate number of cycles (more than 800). Obtaining the optimal parameters for an accurate diagnosis (compression ratio, angular positioning, pressure offset and heat transfer coefficients) is made by the use of genetic algorithms in a non-biased way. As the procedure of combustion diagnosis is automatically and objectively made, it allows studying an elevated number of cycles.

The classic cyclic dispersion estimators such as the coefficient of variation and the standard deviation of IMEP, maximum pressure and combustion length have been applied to the experimental conditions. Additionally a new estimator of cyclic dispersion is proposed, the standard deviation of the mass fraction burning rate ( $\sigma_{\mathrm{MFBR}}$. The general trend of these four estimators for cyclic dispersion is the same when equivalence ratio is modified from stoichiometry to lean limit of operation.

Starting with the relationship between the mass fraction burning rate and the turbulent combustion velocity, once an ensemble average is made for the all recorded pressure traces with the variables expressed as dependent on the mass fraction burned, the relationship between the ensemble average mass fraction burning rate and the combustion velocity is more robust, since the averaging procedure eliminates the influence of variations of density and flame front surface. This means that the ensemble average of mass fraction burning rate is a good estimator of turbulent combustion velocity.

Analogously, the standard deviation of mass fraction burning rate is a good estimator of the turbulent fluctuation of combustion velocity, provided that the variables are ensemble averaged for the corresponding values of the mass fraction burned.

When the ensemble averaged mass fraction burning rate is plotted as a function of mass fraction burned, it shows a dependency on engine rpm (that is almost linear) and also on equivalence ratio. This is in agreement with the well known fact that turbulent combustion depends linearly on flow turbulent intensity and also on equivalence ratio due to the effect of the latter on laminar combustion velocity.

However, when the standard deviation of mass fraction burning rate is plotted as a function of mass fraction burned, there is linear dependence on engine rpm, but a very weak dependence on equivalence ratio. This means that the proposed estimator of cyclic dispersion is sensitive only to flow turbulent intensity and not to equivalence ratio. Since the classical estimators of cyclic dispersion have values that vary due to both causes, it is not possible with them to identify the individual effects. However that can be done with the proposed estimator, based on establishing a functional dependence on mass fraction burned.

\section{Acknowledgments}

The authors of this work would like to thank the Spanish Ministry of Science and Innovation for the financial support of this research through the ENE 2012-34830 (with FEDER funds) and the Regional Government of Castile and Leon for funding the Excellence Research Group GR203.

\section{References}

[1] Naber JD, Siebers DL, Di Julio SS, Westbrook CK. Effects of natural gas composition on ignition delay under diesel conditions. Combust Flame 1994;99:192-200.

[2] El-Sherif AS. Effects of natural gas composition on the nitrogen oxide, flame structure and burning velocity under laminar premixed flame conditions. Fuel 1998;77:1539-47. 
[3] Das LM, Gulati R, Gupta PK. A comparative evaluation of the performance characteristics of a spark ignition engine using hydrogen and compressed natural gas as alternative fuels. Int J Hydrogen Energy 2000;25:783-93.

[4] Heywood JB. Internal combustion engine fundamentals. McGraw-Hill; 1988.

[5] Wendeker M, Litak G, Czarnigowski J, Szabelski, K. Nonperiodic oscillations of pressure in a spark ignition engine. ArXiv Nonlinear Sciences e-prints.

[6] Galloni. Analyses about parameters that affect cyclic variation in a spark ignition engine. Appl Therm Eng 2009;29(5-6):1131-7.

[7] Tinaut F, Giménez B, Horrillo A, Cabaco G. Use of multizone combustion models to analyze and predict the effect of cyclic variations on SI engines. Society of Automotive Engineers, SAE Paper 2000:2000-1-0961.

[8] Litak G, Kaminski T, Czarnigowski J, Czarnigowski D, Wendeker M. Cycle-tocycle oscillations of heat release in a spark ignition engine. Meccanica 2007;42:423-33.

[9] Litak G, Kaminski T, Rusinek R, Czarnigowski J, Wendeker M. Patterns in the combustion process in a spark ignition engine. Chaos Solitons Fractals 2008;35(3):78-585.

[10] Litak G, Kaminski T, Czarnigowski J, Sen A, Wendeker M. Combustion process in a spark ignition engine: analysis of cyclic peak pressure and peak pressure angle oscillations. Meccanica 2009;44:1-11.

[11] Selim MY. Effect of engine parameters and gaseous fuel type on the cyclic variability of dual fuel engines. Fuel 2005;84(7-8):961-71.

[12] Hill PG. Cyclic variations and turbulence structure in spark-ignition engines. Combust Flame 1988;72(1):73-89.

[13] Hill PG, Kapil A. The relationship between cyclic variations in spark-ignition engines and the small structure of turbulence. Combust Flame 1989;78(2):237-47.

[14] Ebrahimi R, Desmet B. An experimental investigation on engine speed and cyclic dispersion in an HCCI engine. Fuel 2010;89(8):2149-56.

[15] Özkan M. Comparative study of the effect of biodiesel and diesel fuel on a compression ignition engine's performance, emissions, and its cycle by cycle variations. Energy Fuel 2007:21:3627-36.

[16] Vermorel O, Richard S, Colin O, Angelberger C, Benkenida A, Veynante D. Towards the understanding of cyclic variability in a spark ignited engine using multi-cycle LES. Combust Flame 2009;156(8):1525-41.

[17] Zheng J, Huang Z, Wang J, Wang B, Ning D, Zhang Y. Effect of compression ratio on cycle-by-cycle variations in a natural gas direct injection engine. Energy Fuel 2009;23:5357-66.

[18] Peucheret S, Wyszynski M, Lehrle $\mathrm{R}$, Golunski $\mathrm{S}, \mathrm{Xu} \mathrm{H}$. Use of catalytic reforming to aid natural gas $\mathrm{HCCl}$ combustion in engines: experimental and modelling results of open-loop fuel reforming. Int J Hydrogen Energy 2005;30(15):1583-94.
[19] Ma F, Ding S, Wang Y, Wang Y, Wang J, Zhao S. Study on combustion behaviors and cycle-by-cycle variations in a turbocharged lean burn natural gas S.I. engine with hydrogen enrichment. Int J Hydrogen Energy 2008;33:7245-55.

[20] Huang B, Hu E, Huang Z, Zheng J. Cycle-by-cycle variations in a spark ignition engine fueled with natural gas-hydrogen blends combined with EGR. Int J Hydrogen Energy 2009;34(19):8405-14.

[21] Wang J, Chen H, Liu B, Huang Z. Study of cycle-by-cycle variations of a spark ignition engine fuelled with natural gas-hydrogen blends. Int J Hydrogen Energy 2008;33(18):4876-83.

[22] Huang Z, Liu L, Jiang D, Ren Y, Liu B, Zeng K, et al. Study on cycle-by-cycle variations of combustion in a direct-injection natural gas engine. Proc Inst Mech Eng J Automobile Eng 2008;222(9):1657-67.

[23] Li G, Yao B. Nonlinear dynamics of cycle-to-cycle combustion variations in a lean-burn natural gas engine. Appl Therm Eng 2008;28(5-6):611-20.

[24] Reyes M, Melgar A, Pérez A, Giménez B. Study of the cycle-to-cycle variations of an internal combustion engine fuelled with natural gas/hydrogen blends from the diagnosis of combustion pressure. Int J Hydrogen Energy 2013;38:15477-87.

[25] Holland J. Control, and artifical intelligence. Cambridge: MIT Press; 1998.

[26] Hernández JJ, Ballesteros R, Sanz-Argent J. Reduction of kinetic mechanisms for fuel oxidation through genetic algorithms. Math Comput Model 2010;52(7-8):1185-93.

[27] Gosselin L, Tye-Gingras M, Mathieu-Potvin F. Review of utilization of genetic algorithms in heat transfer problems. Int J Heat Mass Trans 2009;52(910):2169-88.

[28] Arcoumanis TKC. Flow and combustion in reciprocating engines. Berlin Heidelberg: Springer-Verlag; 2008.

[29] Fraser FBRA. Cycle-resolved LDV integral length scale measurements investigating clearance height scaling, isotropy, and homogeneity in an I.C. engine. Society of Automotive Engineers Paper 1989; SAE Paper:890615.

[30] Aleiferis PG, Hardalupas Y, Taylor AMKP, Ishii K, Urata Y. Flame chemiluminescence studies of cyclic combustion variations and air-to-fuel ratio of the reacting mixture in a lean-burn stratified-charge spark-ignition engine. Combust Flame 2004;136(1-2):72-90.

[31] Hong CW, Chen DG. Direct measurements of in-cylinder integral length scales of a transparent engine. Exp Fluids 1997;23:113-20.

[32] NIST Chemistry Webbook (12 2010). URL <http://webbook.nist.gov/chemistry/>.

[33] Woschni G. A universally applicable equation for the instantaneous hat transfer coefficient in the internal combustion engine. Society of Automotive Engineers 1967; SAE Paper:670931.

[34] Tunestal P. Self-tuning gross heat release computation for internal combustion engines. Control Eng Pract 2009;17(4):518-24. 